\title{
Implementing Health in All Policies - Time and Ideas Matter Too!

\author{
Comment on "Understanding the Role of Public Administration in Implementing Action on \\ the Social Determinants of Health and Health Inequities"
}

\section{Carole Clavier*}

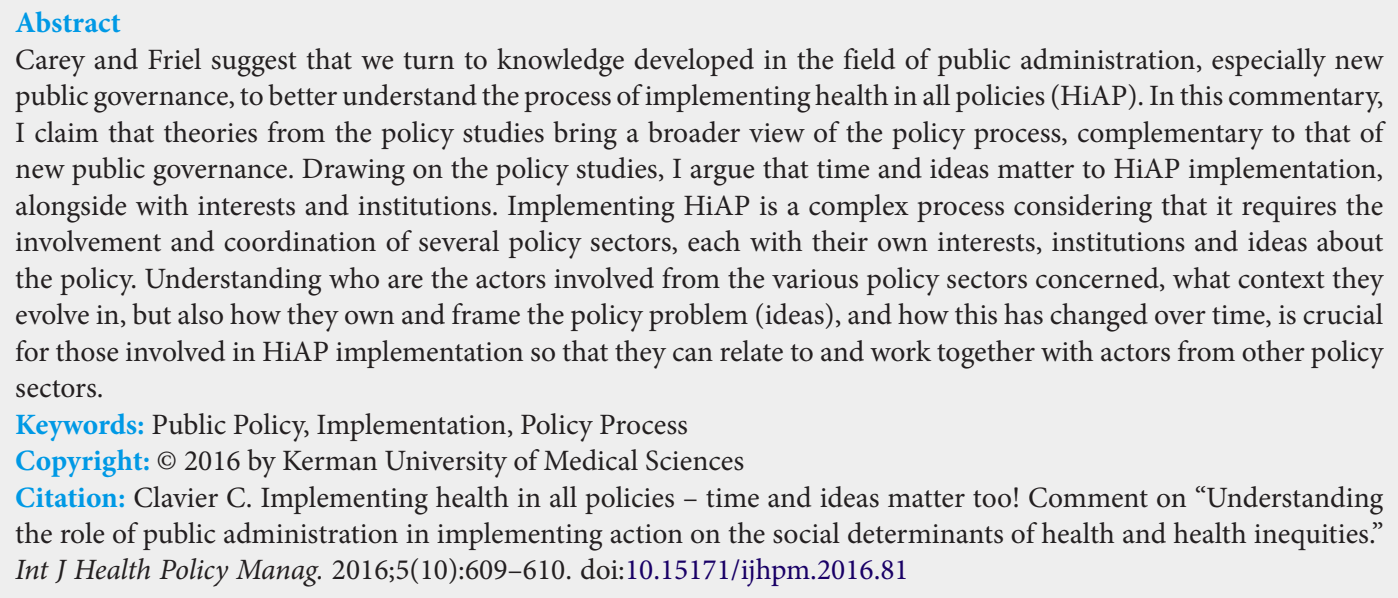
public governance, to better understand the process of implementing health in all policies (HiAP). In this commentary, I claim that theories from the policy studies bring a broader view of the policy process, complementary to that of new public governance. Drawing on the policy studies, I argue that time and ideas matter to HiAP implementation, alongside with interests and institutions. Implementing $\mathrm{HiAP}$ is a complex process considering that it requires the involvement and coordination of several policy sectors, each with their own interests, institutions and ideas about the policy. Understanding who are the actors involved from the various policy sectors concerned, what context they evolve in, but also how they own and frame the policy problem (ideas), and how this has changed over time, is crucial for those involved in HiAP implementation so that they can relate to and work together with actors from other policy sectors.

Keywords: Public Policy, Implementation, Policy Process Copyright: (c) 2016 by Kerman University of Medical Sciences

Citation: Clavier C. Implementing health in all policies - time and ideas matter too! Comment on "Understanding the role of public administration in implementing action on the social determinants of health and health inequities." Int J Health Policy Manag. 2016;5(10):609-610. doi:10.15171/ijhpm.2016.81

\section{Article History:}

Received: 19 February 2016 Accepted: 11 June 2016 ePublished: 20 June 2016
$\mathrm{H}$ ow can we better understand the process of implementing health in all policies (HiAP), whereby different policy sectors seek to take into account the health impacts of their policies through coordinated action? From the Ottawa Charter for Health Promotion and its conceptualisation of healthy public policies, to the more systematic HiAP, public health research has refined its conceptual understanding of what it means to coordinate different sector policies-like health, transportation, education, or agriculture-to take into account the effect of what they do on the health of populations. However, formulating and agreeing on HiAP is all but the end of the process. A growing body of research now focuses on the specific challenges of implementing HiAP. ${ }^{1-4}$

What Carey and Friel ${ }^{5}$ propose in their paper is to draw on theories from public administration research and, to some extent, on studies of the policy process, so as to propose theoretical insights into how we think about the implementation of HiAP. Their argument rests on two premises: (1) Public administrations are at the core of the implementation process given that they are responsible for carrying out policy decisions. Public administrations do not act alone as they are part of a policy process that encompasses a whole range of political, public, private, and community actors. (2) In order to gain a better understanding of how public administrations work together on the social determinants of health across policy sectors, public health researchers need to turn to the conceptual tools of public administration research and the policy process, in particular to those of new public governance research. I agree with Carey and Friel on both their premises, with a slight twist. Implementation studies have shown that carrying out a policy leads to re-interpretations of the decision for reasons that range from the ambiguity of the decision and the high number of actors involved, ${ }^{6}$ to the discretionary power of actors responsible for policy implementation ${ }^{7}$ or the lack of participation from the policy's intended publics. ${ }^{8}$ For these reasons, understanding policy implementation requires that we focus on the interactions between the whole range of actors involved, rather than primarily on public administrations. Theories of the policy process developed in the field of the policy studies are especially appropriate to think those interactions between the political, administrative, private, community and expert actors that make up public policies. ${ }^{9,10}$ My twist, therefore, is to rely more strongly on theories of the policy process to understand HiAP implementation.

Such an approach inevitably draws the focus on the reconciliation of the (usually) diverging interests of each of the policy sectors that can influence the social determinants of health and health inequities. Carey and Friel suggest that we broaden the focus beyond the reconciliation of interests to include a 'better understanding of the policy actors and contexts across the diverse policy domains. ${ }^{5}$ In this commentary, I will draw on literature from the policy studies so as to insist on and develop this argument: implementing HiAP is not just about interests, time and ideas matter too!

Shaping the intersection between public health policies and other public policies requires the creation of 'administrative architectures and governance arrangements that support communication, accountability and sustainable services. ${ }^{5}$ As the authors explain, this involves more than the clever 
mechanical arrangements of procedures to form partnerships or joined-up committees. Ideas-whether they are evidence, deeply held values or policy paradigms-are central to this process. ${ }^{11}$ Participants in such committees each hold very specific beliefs about the problem or policy that concerns them all, bring distinct professional knowledge and look at the problem from the perspective of the mission of their own policy sector. Reaching a shared understanding of the policy is always going to be tough. Public health actors in joined-up committees should not assume that evidence speaks for itself, but should work towards framing evidence in ways that resonate with participants from other policy sectors. Carey and Friel suggest that one way forward is to develop the 'soft skills' of people working at the interface between the organizations involved. I would add that these soft skills should go beyond finding a common point of interest between the participants: they should include the ability to frame ideas (evidence, visions, values). ${ }^{12}$ Framing ideas is about adopting a new understanding of the problem or policy. Actors working at the interface between policy sectors within partnerships or joined-up committees are instrumental in tailoring new ways of framing the policy objectives so that they contribute to the social determinants of health and to the other sector's main mission.

The policy studies have developed a complex understanding of the intricate roles of three key variables of the policy process: ideas, institutions and interests. ${ }^{13,14}$ Although this is not always acknowledged explicitly in the theories of the policy process, time plays a great role in making sense of how each variable exerts its influence. Ideas, institutions and interests change according to different time scales. ${ }^{14}$ Interests-what each policy sector stands to gain or to lose in the cooperation-are understood in the short term. Institutions tend to stand in the way of policy change and, therefore, policy actors will seek ways of subverting their inertia by introducing incremental changes. This is a medium term process. Ideas change over the long term: understanding how a problem has been construed over time will help understand why some actors and institutions have taken responsibility for that problem, and why others have been excluded from the policy. For instance, obesity has been framed in different ways over the past century, each frame offering different possibilities for action for public health practitioners. ${ }^{15}$ In the early 20 th century, weight and obesity were construed as a problem of aesthetics, which yielded little possibility for action on the part of social or health authorities. Then, starting from the 1950s, medical practitioners reframed obesity as a medical problem that could be cured through surgery and medically supervised diets. Simultaneously, public health actors reframed the problem when they highlighted the correlation between obesity and social deprivation, consequently creating an opportunity for themselves to own the problem and act upon it. ${ }^{15}$

Implementing HiAP is a complex process. Policy implementation itself is complex because policies are subject to multiple reinterpretations throughout implementation. In the case of HiAP, specific challenges arise from the involvement and coordination of several policy sectors, each with their own interests, institutions and ideas. This is why, drawing on the policy studies, I argued that time and ideas matter to HiAP implementation, alongside with interests and institutions. Granted, changing how a policy problem is construed so that action about this problem may be favourable to population health and equity is a strategy that may facilitate policy implementation in the longer term, rather than in the short term. Nevertheless, those involved in the implementation of HiAP would benefit from insights into each sector's interests, institutions and ideas in the short term too. Understanding who are the actors involved from the various policy sectors concerned, what context they evolve in, but also how they own and frame the policy problem, and how this has changed over time, is crucial for those involved in HiAP implementation so that they can relate to and work together with actors from other policy sectors.

Ethical issues
Not applicable.

Competing interests

Author declares that she has no competing interests.

Author's contribution

$\mathrm{CC}$ is the single author of the paper.

References

1. Hendriks AM, Habraken J, Jansen MW, et al. 'Are we there yet?,' Operationalizing the concept of integrated public health policies. Health Policy. 2014;114(2-3):174-182. doi:10.1016/j. healthpol.2013.10.004

2. Ollila $E$. Health in all policies: from rhetoric to action. Scand $J$ Public Health. 2011;39(Suppl 6):11-18.

3. Kickbusch I, Buckett K. Implementing Health in All Policies: Adelaide 2010. Adelaide: Department of Health, Government of South Australia; 2010.

4. Molnar A, Renahy E, O'Campo P, Muntaner C, Freiler A, Shankardass K. Using win-win strategies to implement health in all policies: a cross-case analysis. PLoS One. 2016;11(2):e0147003. doi:10.1371/journal.pone.0147003

5. Carey G, Friel S. Understanding the role of public administration in implementing action on the social determinants of health and health inequities. Int $J$ Health Policy Manag. 2015;4(12):795798. doi:10.15171/ijhpm.2015.185

6. Pressman J, Wildawsky A. Implementation. Berkeley: University of California Press; 1973.

7. Lipsky M. Street-level bureaucracy: Dilemmas of the Individual in Public Services. New York: Russel Sage Foundation; 1980.

8. Warin $P$. Les politiques publiques face à la non-demande sociale. In: Borraz O, Guiraudon V, eds. Politiques publiques. 2, Changer la société. Paris: Presses de Sciences Po; 2010:287-312.

9. Sabatier PA, ed. Theories of the Policy Process. Cambridge, MA: Westview Press; 2007.

10. Clavier C, de Leeuw E, eds. Health Promotion and the Policy Process. Oxford: Oxford University Press; 2013.

11. Smith K. Beyond Evidence-Based Policy in Public Health: The Interplay of Ideas. New York: Palgrave Macmmillan; 2013.

12. Clavier $C$, Sénéchal $Y$, Vibert $S$, Potvin L. A theory-based model of translation in public health participatory research. Sociol Health IIIn. 2012;34(5):791-805.

13. Hall PA. The role of interests, institutions and ideas in the comparative political economy of the industrialized nations. In: Lichbach M, Zuckerman A, eds. Comparative Politics. Rationality, Culture, and Structure. Cambridge: Cambridge University Press; 1997:174-207.

14. Palier B, Surel Y. Les "Trois I" et l'analyse de l'État en action. Revue Française de Science Politique. 2005;55(1):7-32.

15. Bossy T. Les différentes temporalités du changement: la mise sur agenda de l'obésité en France et au Royaume-Uni. In: Palier B, Surel Y, eds. Quand les politiques changent. Temporalités et niveaux de l'action publique. Paris: L'Harmattan; 2010:145-182. 